Prior knowledge in mathematics and study success in engineering: informational value of learner data collected from a web-based pre-course

\author{
Derr, Katja
}

http://hdl.handle.net/10026.1/11321

10.1080/03043797.2018.1462765

European Journal of Engineering Education

Taylor \& Francis

All content in PEARL is protected by copyright law. Author manuscripts are made available in accordance with publisher policies. Please cite only the published version using the details provided on the item record or document. In the absence of an open licence (e.g. Creative Commons), permissions for further reuse of content should be sought from the publisher or author. 


\author{
(a)
}

\title{
Prior knowledge in mathematics and study success in engineering: informational value of learner data collected from a web-based pre- course
}

\author{
Katja Derr, Reinhold Hübl \& Mohammed Zaki Ahmed
}

To cite this article: Katja Derr, Reinhold Hübl \& Mohammed Zaki Ahmed (2018): Prior knowledge in mathematics and study success in engineering: informational value of learner data collected from a web-based pre-course, European Journal of Engineering Education, DOI: 10.1080/03043797.2018.1462765

To link to this article: https://doi.org/10.1080/03043797.2018.1462765

\section{曲 Published online: 18 Apr 2018.}

Submit your article to this journal 지

Џll Article views: 17

Q View related articles $\sqsubset$

View Crossmark data $\nearrow$ 


\title{
Prior knowledge in mathematics and study success in engineering: informational value of learner data collected from a web-based pre-course
}

\author{
Katja Derr ${ }^{a}$, Reinhold Hübl ${ }^{a}$ and Mohammed Zaki Ahmed ${ }^{b}$

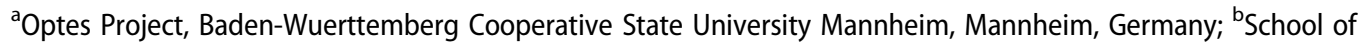 \\ Computing, Electronics and Mathematics, Faculty of Science \& Engineering, Plymouth University, Plymouth, UK
}

\begin{abstract}
The article describes the development and evaluation of a web-based precourse in mathematics, delivered to four cohorts of engineering students at a German university. Based on demographic, personal, and learningrelated data relationships between students' preconditions, their learning gains in the pre-course, and study success in the degree programme were analysed. The results support the existing literature in that domain-related prior knowledge and secondary school achievement play a dominant role regarding study success in engineering. The analyses also showed that the influence of cognitive predictors could only be compensated for by a strong learner engagement. At-risk students with high pre-course learning gains showed significantly better first-year performance. The number of self-tests a student attempted was positively related to pre-course learning gains and even to first-year performance, suggesting that this variable is a good indicator of student engagement.
\end{abstract}

\section{ARTICLE HISTORY}

Received 31 May 2017

Accepted 4 April 2018

\section{KEYWORDS}

Entry test; formative evaluation; mathematics education; pre-course; webbased learning

\section{Introduction and background}

One major characteristic of the transition from secondary to tertiary education today is a high heterogeneity in students' basic skills and knowledge. Particularly in mathematics, many first-year students have considerable gaps; this even applies to freshmen in STEM subjects. Long-term observations of first-year students' knowledge suggest increasing deficits in techniques like rearranging fractions, the application of power and logarithm rules, or the identification of basic functions (Crowther, Thompson, and Cullingford 1997; Lawson 2000; Faulkner, Hannigan, and Gill 2010). The 'mathematics problem' was first addressed in 1995 in the United Kingdom (Howson et al. 1995) but has been subject to discussion in other European countries as well (e.g. Engineering Council 2000). The 'decline', or increase in heterogeneity, may to some extent be related to a growing number of students entering tertiary education (HEFCE 2013). In Germany, for example, the rate of students proceeding to university has grown from 34\% in 2000 to 58\% in 2014 (see report Federal Statistical Office 2016). The differing knowledge levels of German students have also been ascribed to different types of secondary schools and an increase of 'non-traditional' students (Polaczek and Henn 2008), to differing populations and educational policies in German federal states (Pant et al. 2013), and to a revised secondary school curriculum (Knospe 2011).

From a student's point of view, knowledge gaps in mathematics can be considered a risk factor regarding study success. To close secondary school gaps and at the same time keep up with an 
already demanding schedule puts a high strain on their first year at university. Accordingly, the demand for preparatory and bridging courses in mathematics has grown considerably; today, nearly all science and engineering faculties in Germany (and a growing number of business faculties) provide additional mathematics support (Bargel 2015).

In this article, data collected from a web-based pre-course in mathematics administered to four cohorts of prospective engineering students at Baden-Wuerttemberg Cooperative State University (DHBW) Mannheim are reported. Prior achievement, results in a pre-test in mathematics, precourse learning gains, and a set of demographic and personal data were analysed regarding their impact on subsequent achievement.

\subsection{Predictors of study success}

Factors influencing academic achievement have been investigated comprehensively in educational psychology. Amid the digitalisation process in higher education, there also has been a growing interest in learning analytics. Educational data are harvested in order to identify students who are at risk to fail their courses and to suggest interventions at an early stage (Huang and Fang 2013; Marbouti, Diefes-Dux, and Strobel 2015; Sclater, Peasgood, and Mullan 2016).

It is generally agreed upon that secondary and tertiary achievement are strongly related to each other (Harackiewicz et al. 2002; Kuncel and Hezlett 2007; Trapmann et al. 2007). Secondary school grades (leaving certificates, GCSE, or grade point average, GPA), for example, have been found valid predictors of tertiary GPA and of student retention in general, and in particular in STEM subjects (Hell, Linsner, and Kurz 2008; Kokkelenberg and Sinha 2010; Söderlind and Geschwind 2017). For students with a high level of domain-related prior knowledge, it comes easier to acquire new knowledge; thus, in technical degree programmes, mathematics grades (Faulkner, Hannigan, and Gill 2010; Hall et al. 2015) or mathematics placement test scores have also been found predictive of later study success (Zhang et al. 2004; Ehrenberg 2010; Faulkner, Hannigan, and Gill 2010; Greefrath, Koepf, and Neugebauer 2016). The literature also suggests a higher risk for students who attended a vocational school and for students with non-traditional backgrounds (Faulkner, Hannigan, and Fitzmaurice 2014; van Soom, Donche, and Costa 2014).

Although a dominant influence of cognitive variables can be stated, affective and metacognitive variables are considered influential, as well. Students' attitudes towards a subject are likely to impact their motivation to learn. It also could be shown that attitudes correlate with students' confidence and self-beliefs (Pintrich and de Groot 1990; Meyer and Eley 1999). Methodologically, it has been found difficult to separate cognitive and motivational variables as students with a high level of prior knowledge are also more likely to have positive attitudes towards learning and to be efficient self-regulated learners.

In a multiple analysis on academic achievement in STEM, Ackerman, Kanfer, and Beier (2013) compared the impact of performance-related variables and a set of non-traditional trait complexes (personality, motivation, self-regulation, self-concept, self-estimates of ability). With an isolated $R^{2}$ of .21 , mathematics placement test results had a particularly strong influence on tertiary GPA, whereas trait complexes in isolation accounted for $5-8 \%$. With the complete model, $40 \%$ of the variance in cumulated GPA could be explained. Out of the five trait complexes, students' self-concepts in mathematics (their self-confidence and attitudes towards the subject) and their ability to master and organise learning most strongly contributed to predicting achievement in STEM.

Thus affective and metacognitive factors are likely to contribute to predictor models, but seldom outperform cognitive or school-related variables (Hailikari, Nevgi, and Komulainen 2008; Richardson, Abraham, and Bond 2012; Rach and Heinze 2017). To some extent, this effect may be ascribed to the difficulty to model non-traditional variables in a linear manner (Eley and Meyer 2004; Robbins et al. 2004). It also should be pointed out that even in strong models, a lot of variance remains unaccounted for; this particularly applies to the prediction of student withdrawal which is usually influenced by a multitude of factors (Besterfield-Sacre, Atman, and Shuman 1997; Heublein and Wolter 2011). 


\subsection{Study interest}

(1) Based on the literature, a strong correlation between prior performance, domain-related prior knowledge, and study success in engineering is assumed. Can these relationships be reproduced with the data collected for this study and can we identify at-risk students?

(2) Which of the variables collected from the learning management system (LMS) deliver meaningful and consistent results? Which factors are most influential regarding learning gains of the at-risk group?

(3) Can pre-course data be related to study success in engineering? Did pre-course participation improve at-risk students' starting position?

\section{Method}

\subsection{Project background}

The study was conducted at the school of technology at DHBW Mannheim. The analyses reported in this article are based on data collected from four cohorts (first-year students 2011-2014; $N=2967$ ) enrolled in five technical degree programmes (computer science, electrical engineering, mechanical engineering, mechatronics, and industrial engineering). Note that in this period of time, there was a school reform in some German federal states; secondary education was reduced from nine to eight years, resulting in higher numbers of students in 2012 and 2013.

For the analyses, pre-course learner data (test results, questionnaire responses, and log files) and data collected from the university's administration were available. In the privacy statement, students were informed on the background of the study and that all data would be anonymised for evaluation.

The first three years of the study were used to develop, evaluate, and modify the pre-course programme (see Derr, Hübl, and Ahmed 2015). In this paper, the focus will be on the pre-course results of the cohort of 2014 who participated in the revised programme as described in the following section.

\subsection{Pre-course design}

\subsubsection{Diagnostic pre-test in mathematics}

The e-learning environment may be accessed in June. Pre-course participation is not mandatory but via the university's homepage and mailing lists, students are encouraged to (at the least) test their mathematics knowledge. The two-hour diagnostic self-test covers 10 mathematical fields (from Arithmetic to Vectors), each addressed by a set of items (total: 77 test items).

\subsubsection{Learning modules}

After submitting the test, students receive a diagnostic feedback, suggesting learning contents if test results in a mathematical field are below 50\%. Six out of the 10 learning modules cover the basic mathematics school curriculum and can be regarded as repetition (1 Arithmetic; 2 Equations; 3 Powers, roots, and logarithms; 4 Functions; 5 Geometry; and 6 Trigonometry), whereas 4 optional learning modules are only suggested for students who feel confident in the basic curriculum (Real numbers, Vectors, Continuous functions) or for students enrolled in computer science (Logic) (see also recommendations by SEFI Mathematics Working Group 2013; COSH 2014). The web-based learning contents provide texts, graphs, animations and videos, examples, and exercises. At the end of each module, students can take a subject-related self-assessment, consisting of 10-15 randomised items. Feedback to this test comprises a general feedback and detailed solutions for every problem. 


\subsubsection{Additional support}

Students who want additional support may enrol in week-long on-campus courses or a one-month e-tutoring course in September. All students have access to the same web-based learning material, but in the e-tutoring course, the learning process is structured and monitored by mathematics lecturers. The e-tutors help students to organise their learning, encourage them to discuss mathematical problems with peers, and give feedback to weekly uploaded exercise sheets.

\subsubsection{Post-test}

The post-test is taken at the university's computer laboratories during the induction week. Both preand post-test items address the above-mentioned mathematical fields and are on the same difficulty level, but the post-test is much shorter (40 items and 1 hour time limit). The gain score, or difference between post-test and pre-test results, is interpreted as a measure of learning outcome. Note that the pre-post-test design underwent a thorough revision process from 2011 to 2013. Based on these cohorts' test results, item analyses were performed that helped to identify outlying or unfit items (for details, see Derr, Hübl, and Ahmed 2015). Pre-post-test similarity was established by comparing pre-test results with post-test results of students that had neither participated in the pre-test nor in the pre-course.

\subsection{Data collection}

\subsubsection{Dependent variables (study success)}

Cumulated GPA at the end of the degree programme and the dichotomous variable retention (graduation $=1$, withdrawal $=0$ ) were available for the cohorts 2011 to 2013. In addition, the examination Mathematics I was identified as a first-year indicator of study success. In correlation analyses with final GPA, it outperformed all other first-year exams (2011: $r=.62, n=660 ; 2012: r=.62, n=776$; 2013: $r=.70, n=665 ; p<.01)$. By comparison, the exam Construction I (mechanical engineering) had a correlation coefficient between $r=.34$ and .36 , whereas Physics had a correlation coefficient of $r=.57$. A simple linear regression model using Mathematics I as a predictor of GPA was also significant $(p<.01)$ and explained up to $43 \%$ of the variance in GPA.

Mathematics I was also significantly related to retention in a binary logistic regression $(p<.01)$, suggesting that students with poor performance in this exam were more likely to withdraw from the degree programme. This estimation generated many outlying values; thus, the model was less reliable than the linear regression with GPA. However, compared to other first-year exams, Mathematics I showed the strongest relation to overall study success and was considered a good early predictor of study success in engineering. This confirmed that Mathematics I could be used as dependent variable in the 2014 analyses.

\subsubsection{Independent variables (=preconditions)}

Altogether eight independent variables describing students' preconditions when entering university were collected: demographic information (gender, age, gap between secondary and tertiary education, and state of origin), school-related variables (type of secondary school, secondary school GPA, and mathematics grades), and prior knowledge in mathematics (diagnostic pre-test results in per cent). It was hypothesised that all performance-related measures would strongly correlate with the dependent variables Mathematics I, cumulated GPA, and graduation (Figure 1).

Learning gains in the pre-course were represented by the difference between pre-test and posttest results. It was expected that pre-course participation would positively affect this gain score and that a high student engagement would correlate with this score.

It also was assumed that affective variables like attitude towards mathematics and mathematics learning would be influential; these were measured by two subscales from the 'Trends in International Mathematics and Science Study'. In the TIMSS subscale, 'liking mathematics' students' feelings 


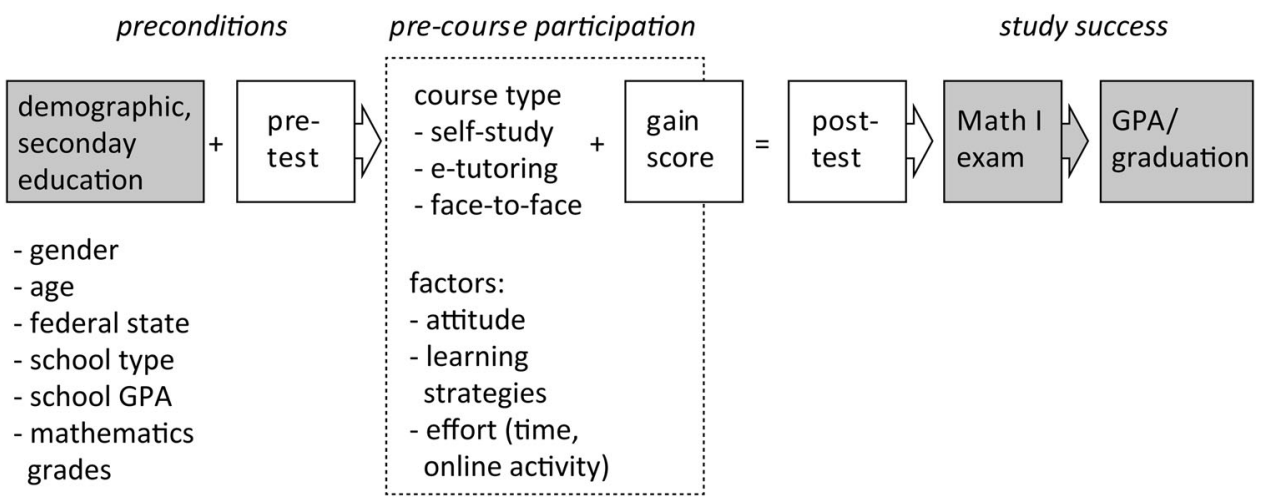

Figure 1. Overview of collected variables: preconditions, pre-course participation, and study success.

towards the subject are addressed, for example 'I am interested in mathematics' or 'I like learning mathematics'. The subscale 'self-confidence in learning mathematics' is represented by items like 'I learn things quickly in mathematics' (Kadijevich 2006, 41f; Mullis et al. 2012, 333f).

A second Likert scale was administered at the end of the pre-course, referring to students' use of learning strategies. The LIST inventory (Schiefele and Wild 1994) is a German adaptation of the 'Motivated Strategies for Learning Questionnaire MSLQ' (Pintrich et al. 1991). Seven items from the subsets 'Cognitive and metacognitive Strategies' and 'Resource management strategies' were revised to address pre-course participants' use of learning strategies (for example 'I always followed a certain learning schedule' from the subscale 'Time and study environment').

Students' effort and engagement in the learning process were also represented by self-reports and LMS log files: In the evaluation questionnaire, students answered how many learning modules they had studied and how much time per week they had learned. The log files informed on the number of learning module page views, the number of test attempts (randomised self-tests provided at the end of each module), and the number of forum posts (in the e-tutoring course). A proficient use of learning strategies and a high level of learner activity was expected to result in higher learning gains in the pre-course.

\subsection{Sample}

In 2014, 84\% of all first-year engineering students took both tests (diagnostic pre-test and post-test). For the analysis, these students were ascribed to the group of 'pre-course participants', regardless of their level of learning activity. About a third of all pre-course participants chose to enrol in at least one additional programme. One hundred and nineteen students participated in a week-long face-to-face course, and 113 students completed the one-month e-tutoring course with a certificate (attrition rate in this course was 14\%). A group of 28 students attended both additional programmes.

The answer rate of the demographic questionnaire was close to $100 \%$ as these items were administered together with the pre-test. Evaluation answer rates were much lower; in the group of e-tutoring participants, $60 \%$ answered this questionnaire, but when looking at the whole group of pre-course participants, the answer rate was only $34 \%$.

Of all first-year students, $98 \%$ participated in the post-test that was taken at the university's computer labs during induction week. For the regression analysis, data from 674 students who took the first-year examination Mathematics I six months later were available (Table 1).

\subsection{Limitations}

E-learning environments have made course evaluation easier in many ways, with a multitude of learner data available for analysis. But not all collected data may deliver meaningful results. In 
Table 1. Pre-course participation, collected data, and first-year students in 2014.

\begin{tabular}{lr}
\hline & $N$ \\
\hline Pre-course participants (=pre-test and post-test participation) & 603 \\
Questionnaire I: personal and attitude scales & 593 \\
Self-study & 386 \\
+ E-tutoring course & 85 \\
+ Face-to-face course & 91 \\
+ E-tutoring and face-to-face course & 28 \\
Questionnaire II: evaluation and learning strategies scales & 200 \\
Enrolled students & 722 \\
$\quad$ Post-test & 708 \\
Post-test only & 105 \\
First-year performance (Mathematics I) & 674 \\
\hline
\end{tabular}

distance education, learner commitment has been found less consistent and students more often drop out, even after initially high interest (Smith and Ferguson 2005; Street 2010; Ashby, Sadera, and Mcnary 2011), an effect particularly observed in open access courses (Pappano 2012). Answer rates in web-based evaluations are often lower, making it difficult to identify reasons for withdrawal (Cook, Heath, and Thompson 2000; Fan and Yan 2010).

In this study, only online or self-reported learner behaviour could be monitored. Thus, students who chose to study with the help of peers, textbooks, or other resources and did not answer the evaluation had the same 'effort' scores as students who eventually did nothing.

It also should be considered that no randomised groups could be used. Due to ethical and organisational reasons, students were free to self-enrol in the different additional course programmes. As learner behaviour is likely to be related to performance measures, a bias will have to be accounted for in all interpretations.

Finally, it might also be discussed if graduation, cumulated GPA, or examination results are exhaustive measures of study success. For reasons of comparability, it seemed appropriate to use these widespread performance measures (Robbins et al. 2004, 262) although alternative approaches to measuring 'success' in an engineering degree programme are certainly conceivable.

\section{Results}

The results are reported alongside the three guiding questions (Section 1.2).

\subsection{Basic model: students' preconditions and study success}

Linear and binary logistic regression analyses verified the assumptions made in Section 1.1. The two variables secondary school GPA and diagnostic pre-test results showed the strongest and most consistent impact on first- and final-year academic achievement, as well as graduation/withdrawal. Whereas secondary school GPA showed a stronger relation to overall study success, pre-test results had a stronger impact on first-year achievement: this variable alone accounted for $21 \%$ of the variance in Mathematics I.

According to the 2014 estimation, each increase in secondary school GPA (plus 1) was related to an increase in Mathematics I of plus .44. A step up in pre-test results (in per cent) was related to an increase in Mathematics I grades of .025 . Thus, students with a pre-test mean score of 40 were predicted Mathematics I grades .5 above those of similar students with a pre-test mean score of 20. (Note that in Germany, GPA and Mathematics I grades range on a linear scale from 1 to 5; see also Table 5, model 1).

The type of secondary school attended was also found as an important factor, suggesting significantly poorer performance for students from vocational schools and for students with non-traditional backgrounds (Faulkner, Hannigan, and Fitzmaurice 2014; van Soom, Donche, and Costa 2014). 
Mathematics grades at school were also related to Mathematics I, but in the multiple model, this variable showed less powerful results than expected (Zhang et al. 2004; Ehrenberg 2010; Faulkner, Hannigan, and Gill 2010). As pre-test results are also a measure of domain-related prior knowledge, they may have overpowered the impact of grades when added to the model.

Interactions between variables were identified for gender, age, and educational background. Female students, for example, often showed better first-year performance than male students, and in some models, this effect was significant. A descriptive analysis showed that women more often had traditional educational backgrounds and good or very good secondary school grades than male students. After controlling for these interactions, gender was no longer influential. In the literature, investigations of the relation between gender and performance in mathematics or science have led to mixed results (Zhang et al. 2004; Xie and Shauman 2005; Johnson and Kuennen 2006; Richardson, Abraham, and Bond 2012; Faulkner, Hannigan, and Fitzmaurice 2014). As female students are underrepresented in engineering courses (in this study, the average rate was $12 \%$ ), it is generally difficult to separate the influence of gender on academic achievement in engineering (Ackerman, Kanfer, and Beier 2013).

Inconsistent observations were made regarding students' age, with respect to the length of the gap between secondary and tertiary education. Younger students, on average, showed higher first-year performance, and the risk to withdraw appeared to increase with age. Again, these results were moderated by cognitive variables, as traditional students usually are younger than students with a non-traditional background. There also were some heteroscedasticity issues as the majority of students were between 18 and 21 years old, whereas in the much smaller group of older students, the data set was very heterogeneous (ranging from 22 to 49 years of age). It can be drawn from our data that older students tend to withdraw more quickly if they are facing performance issues, but beyond this very weak trend, age appeared to be unrelated to study success.

Some effects were caused by the federal state in which secondary school was attended, suggesting that some of the changes to secondary education in Germany negatively influenced student performance (see also Knospe 2011; Greefrath, Koepf, and Neugebauer 2016). However, with a high interaction with other school-related preconditions, these effects are relatively weak and might as well be found irrelevant in the further course of the project.

Overall, up to $37 \%$ of the variance in Mathematics I and up to $36 \%$ of the variance in cumulated GPA could be accounted for by multiple linear regressions. Table 2 shows an overview of the different estimations and the variables that showed a significant contribution. Binary logistic regression with the dichotomous variable retention showed similar relations as the linear regression models, with varying power of secondary school GPA and pre-test results. Although the regression model was significant $(p<.01)$ it also was too weak to predict drop-outs, suggesting that student withdrawal only to

Table 2. Regression analyses results: significant factors in relation to dependent variables Mathematics I (cohorts 2011-2014), cumulated GPA at the end of the degree programme, and retention (2011-2013).

\begin{tabular}{|c|c|c|c|c|c|c|c|c|c|c|}
\hline & \multicolumn{4}{|c|}{ Mathematics I } & \multicolumn{3}{|c|}{ Cum. GPA } & \multicolumn{3}{|c|}{ Retention } \\
\hline & 11 & 12 & 13 & 14 & 11 & 12 & 13 & 11 & 12 & 13 \\
\hline$n$ & 383 & 524 & 482 & 465 & 368 & 522 & 479 & 377 & 533 & 496 \\
\hline \multicolumn{11}{|l|}{ Preconditions: } \\
\hline Gender & & * & & & & & & & & \\
\hline Age & & & & & & & & * & & \\
\hline Gap school / university & & * & & & * & * & & * & * & * \\
\hline Federal state & & & & * & * & & * & & & * \\
\hline Type of school & & * & * & & * & * & * & & * & * \\
\hline Mathematics grades at school & * & * & & & & & & & & \\
\hline Secondary school GPA & * & * & * & * & * & * & * & & * & * \\
\hline Diagnostic pre-test result (\%) & * & * & * & * & * & & * & * & & \\
\hline$R^{2}$ & .25 & .26 & .37 & .33 & .31 & .33 & .36 & .24 & .24 & .21 \\
\hline
\end{tabular}


some extent can be described by this data set and probably is affected by a more complex combination of factors (Robbins et al. 2004; Zhang et al. 2004).

These outcomes mirror the literature on academic achievement in engineering, with very stable relations between school performance, prior knowledge level, and success in MINT-related subjects (Budny, LeBold, and Bjedov 1998; Zhang et al. 2004; Kokkelenberg and Sinha 2010; Faulkner, Hannigan, and Fitzmaurice 2014; van Soom, Donche, and Costa 2014). It can be concluded from these analyses that poor values in any of the achievement-related variables, and particularly in secondary school GPA and diagnostic pre-test results, are a risk factor regarding tertiary achievement.

\subsection{Pre-course learning gains}

After having verified the importance of mathematics prior knowledge level for study success in the engineering programme, factors influencing learning gains in the pre-course were investigated. Analyses of variance were performed for each variable on pre-test results and gain score.

In 2014, the 603 students who participated in both tests achieved an average pre-test score of 49.7 (standard deviation $=16.0$ ) and an average post-test score of 55.2 (stand. dev. $=17.5$ ). By comparison, students who had not participated in the pre-test achieved a post-test mean score of $47.3(n=105$; stand. dev. $=18.2$ ). In both samples, variance was rather high, with results ranging from $7 \%$ to $98 \%$. The gain score, as well, had a large variance with a maximum of plus 61.8 and a minimum (negative) gain score of -37.5 . Thus, only $50 \%(n=302)$ obtained a gain score of plus 5 or more, while 186 students had no gains (gain score between +5 and -5 ) and 115 students had a negative gain score (less than -5$)$.

\subsubsection{Course type}

Students who participated in an additional programme had below-average pre-test results (mean score $=45.3 ; n=204$ ) and an average post-test result of 50.9. In this group, pre-post-test difference was significantly affected by the type of course a student chose to attend. Face-to-face course participants, on average, had a gain score of $3.6(n=91)$, whereas students who completed the e-tutoring course had an average gain score of $6.7(n=85)$. The highest learning gains were achieved by students who had participated in both course types, e-tutoring and face-to-face, with an average gain score of 9.1 ( $n=28$, pre-test mean score $=44.2$; post-test mean score $=53.3$ ).

It can be seen from Table 3 that in the face-to-face group, pre-test results were even poorer than in the e-tutoring course. Looking at the demographic data, it also seemed that the face-to-face course had been preferred by non-traditional students. Although these between-group differences were not significant, it may be hypothesised that students' preconditions and preferences had an additional influence on the learning outcomes of the face-to-face group.

\subsubsection{Affective and metacognitive variables}

It had been hypothesised that mathematics attitude items would correlate with each other, which they did, thus replicating existing results that suggest relations between mathematics liking and mathematics self-confidence (Parsons, Croft, and Harrison 2009). Significant relations with pre-test results were also found for nearly all attitude items, suggesting that a positive attitude towards mathematics is related to a higher level of prior knowledge. A critical point were the often skewed

Table 3. Pre- and post-test results 2014: complete data set in comparison to chosen pre-course type $(n=603)$.

\begin{tabular}{lccccc}
\hline & Participants both tests & Self-study & Face-to-face & E-tutoring & Face-to-face + e-tutoring \\
\hline$n$ & 603 & 386 & 91 & 85 & 28 \\
Pre-test (\%) & 49.7 & 52.4 & 43.6 & 47.5 & 44.2 \\
Post-test (\%) & 55.2 & 57.9 & 47.2 & 54.2 & 53.3 \\
gain score & 5.5 & 5.5 & 3.5 & 6.7 & 9.1 \\
\hline
\end{tabular}


distributions: participants more often expressed positive attitudes towards mathematics, or felt reluctant to express negative attitudes, leading to small case numbers. For example, only $13 \%(n=77)$ of first-year students were on the negative side of the statement 'I enjoy learning mathematics' (strongly disagree: $n=15$; disagree: $n=62)$, whereas $63 \%$ agreed $(n=277)$ or strongly agreed $(n=89)$. An impact of these scales on gain score could not be observed; particularly in the group of at-risk students, a positive attitude was unrelated to learning outcomes. Two interpretations may be drawn from these results: First of all, engineering students in this study showed very positive attitudes towards mathematics, suggesting that they were well aware of the important role the subject plays in their chosen degree programme. In this context, it also can be hypothesised that students' answers were influenced by social desirability. Very high levels of mathematics liking and confidence, however, were mainly observed for students with a high level of prior knowledge, suggesting that attitudes are more strongly attached to students' preconditions than to their actual learning situation.

Non-normal distributions were also observed for the learning strategies scale. Four items addressing a proficient use of learning strategies were significantly related to each other, and to pre-test results, indicating that students able to manage their learning process had a higher level of prior knowledge in mathematics, as well. However, these relations were never linear, so that these variables only allowed to differentiate between (very good) students who 'strongly agreed' to an item like 'I usually managed to keep to my schedule' $(n=43$; pre-test mean scores $=58.6)$ and the rest of the sample. Thus, the assumption that high levels in the learning strategies scales would be related to high learning gains could not be confirmed. Particularly in the at-risk group, these items were more or less unrelated to gains.

\subsubsection{Effort}

Students' self-reports as well as LMS log files were analysed for the measurement of effort. In the evaluation questionnaire, students had answered how many learning modules they had worked through, how many hours per week they had studied, and how they estimated their overall engagement (Likert-scaled item 'I invested a lot of time into the study preparation'). Analysis of variance showed that students who scored high on these items also showed higher learning gains. The ANOVA, however, was not significant for these variables, with large within-group variation.

The page view count drawn from the LMS database, as well, failed to deliver significant results. Out of the existing 684 learning module pages, the average student visited 240 pages (the median was 121). Students with $0-10$ page views showed poorer gains than the rest of the sample, but otherwise this variable did not significantly explain achievement in the pre-course. Similarly, the number of forum posts in the e-tutoring course was unrelated to learning gains. The e-tutoring groups were highly heterogeneous regarding communication preferences, and the case numbers were too small for statistical interpretation. Analysis of single cases, as well, did not suggest that a high (or low) number of forum posts were related to achievement.

Finally, the number of self-tests per student were analysed. Each learning module provided a final self-assessment, consisting of 10-15 randomised items (thus with each test attempt new items were presented and the number of attempts was unlimited). The highest number of test attempts was 83 , but only a minority took more than 10 tests. Transformed to a five-step ordinal variable, with 'no test attempts', '1-5 attempts', '6-10 attempts', '11-20 attempts', and '21 and more attempts', this variable significantly differentiated between higher/lower achievement in the pre-course (see Table 4). Students with no test attempts had the poorest learning gains (gain score $=3.8$ ), and students with 21 and more attempts had an average gain score of $12.0(p<.01)$.

These results suggest that the number of test attempts is a reliable indicator of students' effort, at least in the domain of mathematics. Macfadyen and Dawson (2010) reported similar results for a biology course - and an even stronger impact of the total number of forum posts, an effect that could not be confirmed by this study. The results also support the view that study time or number of page views are less reliable indicators of student engagement in e-learning environments (Samson 2015). 
Table 4. Pre- and post-test results 2014: complete data set in comparison to number of test attempts $(n=603)$.

\begin{tabular}{lcccccc}
\hline & Participants both tests & No test attempts & $1-5$ attempts & $6-10$ attempts & $11-20$ attempts & $\geq 21$ attempts \\
\hline$n$ & 603 & 296 & 167 & 55 & 60 & 25 \\
Pre-test (\%) & 49.7 & 50.2 & 48.2 & 52.0 & 49.9 & 49.0 \\
Post-test (\%) & 55.2 & 54.0 & 53.7 & 57.2 & 60.4 & 61.0 \\
Gain score & 5.5 & 3.8 & 5.6 & 5.3 & 10.5 & 12.0 \\
\hline
\end{tabular}

\subsection{Complete model: pre-course participation and study success}

Assuming poor pre-test results being a risk factor, pre-course learning gains were expected to reduce this risk. Thus, the gain score was added to the basic model (as described in Section 3.1 and in Table 5, model 2). The gain score significantly contributed to explaining Mathematics I achievement ( $B$ coefficient gain score $=.014$; see Table 5 , model 2 ). Compared to the dominant role of prior knowledge, this effect was not very strong; thus, a noticeable change in Mathematics I was only predicted for students with very high learning gains. For example, a student with a gain score of 20 was predicted an increase in Mathematics I grades by .28 , compared to a similar student with a gain score of 0 (Note that test scores ranged from 0 to 100 and that Mathematics I grades ranged from 1 to 5).

Finally, variables related to pre-course participation were added to the multiple model. The two scales, students' attitudes towards the subject as well as use of learning strategies, had shown skewed or non-linear distributions and thus were excluded from the regression analysis.

The course type a student participated in was not significantly related to performance in Mathematics I. As mainly students with a relatively poor pre-test result participated in an additional course, the impact of this variable was apparently not strong enough to overpower the variables related to prior knowledge. Self-reported study time as well as page view count were unrelated to Mathematics I. In this model, only the number of pre-course test attempts showed a significant contribution (see Table 5, model 2). Even if the effect is relatively small, the results show that high levels of pre-course participation are still visible in the Mathematics I examination which is taken several months later. Table 5 gives a summary of the changes in variance explained $\left(R^{2}\right)$ when gain score and effort (model 2) were added to the basic model 1.

As a final analysis, it was investigated if the group of students who had not participated in the pretest or the pre-course programme $(n=105)$ differed in their Mathematics I results. The multiple model suggested significantly poorer first-year performance for non-participants, leading to a difference of -.5 in Mathematics I grades $(p<.01)$. Similar effects could be observed for the previous cohorts (2011-2014; see Table 6). Accordingly, it could be observed that students who had not participated in the pre-course more often failed this exam (note that in this data set, 'failure' means grades above

Table 5. Summary of hierarchical regression analysis for variables predicting Mathematics I $(n=465)$.

\begin{tabular}{|c|c|c|c|c|c|c|}
\hline & \multicolumn{3}{|c|}{ Model 1} & \multicolumn{3}{|c|}{ Model 2} \\
\hline & $B$ & SE B & $\beta$ & $B$ & $S E B$ & $\beta$ \\
\hline Gender & .14 & .12 & .05 & .08 & .12 & .03 \\
\hline Age & .03 & .05 & .06 & .04 & .04 & .07 \\
\hline Gap school/university & -.04 & .06 & -.04 & -.07 & .06 & -.09 \\
\hline Federal state $^{a}$ & .47 & .15 & $.14^{* *}$ & .32 & .15 & $.10^{*}$ \\
\hline Type of school & .19 & .16 & .09 & .15 & .15 & .07 \\
\hline Mathematics grades & .00 & .15 & .00 & -.07 & .14 & -.03 \\
\hline Secondary school GPA & .44 & .10 & $.23^{* *}$ & .43 & .10 & $.23^{* *}$ \\
\hline Diagnostic pre-test result (\%) & .03 & .00 & $.40^{* *}$ & .03 & .00 & $.43^{* *}$ \\
\hline Gain Score & & & & .01 & .00 & $.14^{* *}$ \\
\hline Number of test attempts & & & & .02 & .01 & $.11^{*}$ \\
\hline$R^{2}$ & & .33 & & & .36 & \\
\hline
\end{tabular}

Note: Model 1: students' preconditions when entering university; Model 2: gain score and number of test attempts added. $B$ : unstandardised regression coefficient; SE B: standard error; $\beta$ : standardised regression coefficient; significance levels ${ }^{a}$ Federal state Baden-Wuerttemberg $=$ baseline.

${ }^{*} p<.05 ;{ }^{* *} p<.01$. 
Table 6. Mathematics 1 results 2011-2014, pre-course participants vs. non-participants.

\begin{tabular}{|c|c|c|c|c|c|c|c|c|}
\hline & \multicolumn{4}{|c|}{ Mathematics I failure rate } & \multicolumn{4}{|c|}{ Mathematics I grades ${ }^{a}$} \\
\hline & 2011 & 2012 & 2013 & 2014 & 2011 & 2012 & 2013 & 2014 \\
\hline Non-participation & 5.1 & 8.7 & 10.2 & 11.7 & 2.8 & 3.1 & 3.0 & 3.3 \\
\hline Participation & 2.5 & 2.6 & 4.8 & 3.0 & 2.6 & 2.6 & 2.8 & 2.8 \\
\hline Total & 3.2 & 3.8 & 5.6 & 4.1 & 2.7 & 2.7 & 2.8 & 2.8 \\
\hline
\end{tabular}

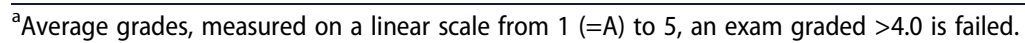

4.0 after one resit and one oral examination). There was an overall increase in Mathematics I failures from 2011 to 2014, which particularly showed in the group of non-participants.

The effectiveness of the pre-course thus could be established, considering the above-mentioned limitations. Descriptive analyses suggested that the rate of at-risk students in the posttest-only group was slightly higher, with more students having attended vocational schools and a higher rate of medium to poor school grades. These differences were not significant, with a high variance and a considerable number of very high performing students. However, it may be hypothesised that students who take the diagnostic pre-test and participate in the precourse already show a higher interest in their degree programme, which might result in better first-year performance.

\section{Discussion}

Major assumptions regarding relations between prior achievement, domain-related prior knowledge, and study success in engineering could be reproduced in this study (Zhang et al. 2004; Hell, Linsner, and Kurz 2008; Ackerman, Kanfer, and Beier 2013; Hall et al. 2015). In a multiple model secondary school, GPA and results in the mathematics pre-test were found to be the strongest predictors of first- and final-year achievement. The type of secondary school was also found to be a significant factor, putting students from vocational schools and students with non-traditional backgrounds at a disadvantage. Other variables, like gender, age, or German federal state, were repeatedly found to interact with school-related and cognitive variables. After controlling for these interferences, demographic variables were no longer significantly related to study success.

After having confirmed the assumption that gaps in basic mathematics knowledge significantly affect students' chances to succeed, it was investigated if pre-course participation would improve these chances. The analyses revealed significantly higher first-year performance in mathematics for students who participated in the pre-course than for students who did not. Over a period of four years, this accounted for up to .5 grades in the Mathematics I exam. Given the lack of randomisation and an overall high variance, these outcomes should not be overrated; pre-course participation not necessarily led to good first-year performance. However, non-participation certainly added to the risk of students with poor prior knowledge.

Some of the results in this study demand further analyses, for example the considerable number of students who obtained only small or even negative gain scores. Many students probably did not study a lot, as suggested by the log file analyses. Others, however, were unable to benefit from pre-course participation in spite of their learning activities. It is hypothesised that some students' knowledge gaps were too broad or too fundamental to be adequately addressed by a relatively short and compact pre-course. At the moment, we are analysing a follow-up interview study that explores the student perspective more deeply.

Further research may also be needed to better understand the questionnaire answer patterns. The attitude scales, for example, showed that prior achievement correlated with students' attitude towards mathematics: students with a high level of prior knowledge more often expressed very positive attitudes towards learning mathematics. In the group of poor performing students, however, the results were less consistent. While the majority of students' expressed a positive view, their learning 
gains were unrelated to their attitudes towards the subject. The scales thus failed to differentiate between successful and less successful pre-course participation of the at-risk group.

Relatively strong learning gains (post-pre-test difference) were observed for students who had attended an additional e-tutoring programme. This group outperformed face-to-face participants, an effect to some extent caused by differences in course duration and concept. It also was not possible to eliminate the bias caused by self-enrolment. However, it could be observed that the majority of face-to-face students did not engage in online learning activities. These observations are interesting in the light of the analyses of pre-course learner behaviour. The only non-moderated and significant factor regarding learning gains was the number of online test attempts. This variable not only correlated with pre-course learning gains but showed a visible effect on first-year performance in mathematics, as well. Positive, but non-significant influence on learning gains were found for study time, number of learning modules, or self-perceived effort, whereas the number of page visits in the e-learning environment was completely unrelated to learning gains. There remain open questions regarding the low impact of items addressing the use of learning strategies. Ledermüller and Fallmann (2017), as well, were unable to find a mediating effect of learning strategies scales on achievement. In their study on learner behaviour of accounting and management students, only prior knowledge and number of online self-tests significantly affected the exam score at the end of the course. In that context, it has been discussed if self-reports are an adequate approach to measuring learning strategy use (Winne and Jamieson-Noel 2002; Greene and Azevedo 2010). High performing students may find it easier to answer metacognitive items (Case 2004), and they also are more likely to answer them consistently (Thiessen and Blasius 2008). Alternative approaches have been suggested, for example using e-portfolios for more comprehensive monitoring of learning activities. But working with such tools demands time, effort, and conscientiousness and can be considered a metacognitive strategy in itself (Zimmerman et al. 2011). Future research will show if more advanced learning analytics tools provide more consistent observations of learner behaviour (Gibson and Ifenthaler 2017). Such technical solutions might also solve issues of non-response or social desirability. In this study, it could only be hypothesised why students did not answer the evaluation, a question that will have to be addressed in further qualitative analyses.

Concluding, what implications for the design of pre-courses in mathematics can be made based on this study? First, it could be shown that entering students' mathematical skills indeed are heterogeneous in many ways. The average pre-test results of non-traditional students, for example, were significantly poorer than those of traditional students, but in both groups there was a very large variance. Knowledge gaps could be observed in all ten mathematical areas, and our results did not indicate that some were more relevant for study success in engineering than others. It is suggested that either 'basic knowledge in mathematics' is a more general concept that cannot be narrowed down to certain topics - or that our instruments lacked the accuracy to clearly differentiate between the ten knowledge areas.

Second, formative self-assessment could be identified as an effective learning strategy in the context of knowledge re-activation, basic skill training and consolidation. Engaging in self-tests not only was positively related to learning gains, the evaluation also revealed that students highly appreciated opportunities to practice and self-monitor their learning. The role of engagement and of practice in the self-study process will be investigated more deeply in the further course of the project. It is hypothesised that the willingness to take self-tests is a good indicator of students' overall engagement (Gibbs and Simpson 2004; Pachman, Sweller, and Kalyuga 2013). However, our analyses also reveal that a considerable number of students did not make use of the provided tools.

Therefore, as a third aspect, more needs to be done to engage students in formative self-assessment. Previous research has shown that inexperienced students tend to procrastinate and thus benefit from guided and structured course designs (Artino and Stephens 2009). It seems plausible that the more binding character of the e-tutored course in this study had a positive effect on the at-risk group, therefore similar course structures should be applied to the face-to-face sessions. 
Finally, the potential of predictive models for engineering education in the transition phase is discussed. Correlations between prior knowledge, prior performance, and subsequent performance are well-documented (Hattie 2009); the reproduction of such relations helped to establish external validity in this study. At the same time, a lot of information was missing. With more than $60 \%$ of variance unaccounted for, many students in this study showed a good Mathematics I performance in spite of a poor pre-test result and there also remained a number of students who performed reasonably well in the pre-test yet failed their first exam. It is therefore not recommended to 'predict' study success (or failure) of an individual student. We do however suggest informing pre-course participants of the outcomes of such studies. In an abridged version, elements of this report were made available for tutors and students (see www.optes.de) and can be used to discuss test scores with students and thus raise awareness for the role of basic knowledge in mathematics.

\section{Acknowledgements}

Responsibility for the content published in this article, including any opinions expressed therein, rests exclusively with the authors. Test items and learning material are licenced under the creative commons attribution 3.0 unported and can be provided via www.optes.de.

\section{Disclosure statement}

No potential conflict of interest was reported by the authors.

\section{Funding}

Support for this publication was provided by the German Federal Ministry of Education and Research (BMBF) in the context of the Federal 'Quality pact for teaching' (ref. number 01PL17012A).

\section{Notes on contributors}

Katja Derr worked in the field of e-learning design and development before completing a degree in education at Freiburg University of Education. Since 2007, she has been involved in mathematics e-learning projects in tertiary education, since 2012 she is a research staff member in the joint project optes.

Reinhold Hübl received his $\mathrm{PhD}$ in mathematics from the University of Regensburg in 1987. After working in mathematical research and software development for several years, he joined the staff of DHBW Mannheim in 2009 where he teaches mathematics and acts as scientific coordinator of the centre of basic knowledge in mathematics and sciences.

Mohammed Zaki Ahmed received his PhD in electrical engineering from Plymouth University in 2003. He works in signal processing research and manages the MEng and BEng programmes in Electrical and Electronic Engineering at Plymouth University.

\section{References}

Ackerman, Phillip L., Ruth Kanfer, and Margaret E. Beier. 2013. “Trait Complex, Cognitive Ability, and Domain Knowledge Predictors of Baccalaureate Success, STEM Persistence and Gender Differences." Journal of Educational Psychology 105 (3): 911-927.

Artino, Anthony R., and Jason M. Stephens. 2009. "Academic Motivation and Self-Regulation: A Comparative Analysis of Undergraduate and Graduate Students Learning Online." The Internet and Higher Education 12: 146-151.

Ashby, Jean, William A. Sadera, and Scot W. Mcnary. 2011. "Comparing Student Success Between Developmental Math Courses Offered Online, Blended, and Face-to-Face." Journal of Interactive Online Learning 10 (3): 128-140.

Bargel, Tino. 2015. Studieneingangsphase und heterogene Studentenschaft - neue Angebote und ihr Nutzen: Befunde des 12. Studierendensurveys an Universitäten und Fachhochschulen. Hefte zur Bildungs- und Hochschulforschung 83. Konstanz: AG Hochschulforschung University of Konstanz.

Besterfield-Sacre, Mary, Cynthia J. Atman, and Larry J. Shuman. 1997. "Characteristics of Freshman Engineering Students: Models for Determining Student Attrition in Engineering." Journal of Engineering Education 86 (2): 139-149.

Budny, Dan, William LeBold, and Goranka Bjedov. 1998. "Assessment of the Impact of Freshman Engineering Courses." Journal of Engineering Education 87 (4): 405-411. 
Case, Jennifer. 2004. "Approaches to Learning: A Critical Examination of Inventory Responses from Third Year Chemical Engineering Students." Proceedings of the 12th Annual Conference of the Southern African Association for Research in Mathematics, Science and Technology Education SAARMSTE, Cape Town, 102-110.

Cook, Colleen, Fred Heath, and Russel L. Thompson. 2000. "A Meta-Analysis of Response Rates in Web- or Internet-Based Surveys." Educational and Psychological Measurement 60 (6): 821-836.

COSH cooperation schule:hochschule. 2014. "Mindestanforderungskatalog Mathematik (2.0) der Hochschulen BadenWürttembergs für ein Studium von WiMINT-Fächern.". Accessed May 26, 2017. http://www.mathematik-schulehochschule.de/images/Aktuelles/pdf/MAKatalog_2_0.pdf.

Crowther, K., D. Thompson, and C. Cullingford. 1997. "Engineering Degree Students Are Deficient in Mathematical Expertise - Why?" International Journal of Mathematical Education in Science and Technology 28 (6): 785-792.

Derr, Katja, Reinhold Hübl, and Mohammed Z. Ahmed. 2015. "Using Test Data for Successive Refinement of an Online PreCourse in Mathematics." Proceedings of the 14th European Conference on e-Learning ECEL, Hatfield, 173-180.

Ehrenberg, Ronald G. 2010. "Analyzing the Factors That Influence Persistence Rates in STEM Field, Majors: Introduction to the Symposium." Economics of Education Review 29: 888-891.

Eley, Malcolm G., and J. H. F. Meyer. 2004. "Modelling the Influences on Learning Outcomes of Study Processes in University Mathematics." Higher Education 47 (4): 437-454.

Engineering Council. 2000. Measuring the Mathematics Problem. Joint Report, London. Accessed March 16, 2018. http:// www.engc.org.uk/EngCDocuments/Internet/Website/Measuring\%20the\%20Mathematic\%20Problems.pdf.

Fan, Weimiao, and Zheng Yan. 2010. "Factors Affecting Response Rates of the Web Survey: A Systematic Review." Computers in Human Behavior 26: 132-139.

Faulkner, Fiona, Ailish Hannigan, and Olivia Fitzmaurice. 2014. "The Role of Prior Mathematical Experience in Predicting Mathematics Performance in Higher Education." International Journal of Mathematical Education in Science and Technology 45 (5): 648-667.

Faulkner, Fiona, Ailish Hannigan, and Olivia Gill. 2010. "Trends in the Mathematical Competency of University Entrants in Ireland by Leaving Certificate Mathematics Grade." Teaching Mathematics and Its Applications 29 (2): 76-93.

Federal Statistical Office (Statistisches Bundesamt). 2016. Hochschulen auf einen Blick. destatis. Wiesbaden. Accessed March 1, 2017. www.destatis.de/EN.html.

Gibbs, Graham, and Claire Simpson. 2004. "Conditions Under Which Assessment Supports Student Learning." Learning and Teaching in Higher Education 1 (1): 3-31.

Gibson, David C., and Dirk Ifenthaler. 2017. "Preparing the Next Generation of Education Researchers for Big Data in Higher Education." In Big Data and Learning Analytics in Higher Education: Current Theory and Practice, edited by Ben K. Daniel, 29-42. Basel: Springer.

Greefrath, Gilbert, Wolfram Koepf, and Christoph Neugebauer. 2016. "Is There a Link Between Preparatory Course Attendance and Academic Success? A Case Study of Degree Programmes in Electrical Engineering and Computer Science." International Journal of Research in Undergraduate Mathematics Education 3: 143-167.

Greene, Jeffrey A., and Roger Azevedo. 2010. "The Measurement of Learners' Self-Regulated Cognitive and Metacognitive Processes While Using Computer-Based Learning Environments." Educational Psychologist, 45 (4): 203-209.

Hailikari, Telle, Anne Nevgi, and Erkki Komulainen. 2008. "Academic Self-Beliefs and Prior Knowledge as Predictors of Student Achievement in Mathematics: A Structural Model." Educational Psychology 28 (1): 59-71.

Hall, Cathy W., Paul J. Kauffmann, Karl L. Wuensch, William E. Swart, Karen A. DeUrquidi, O. H. Griffin, and C. S. Duncan. 2015. "Aptitude and Personality Traits in Retention of Engineering Students." Journal of Engineering Education 104 (2): 167-188.

Harackiewicz, Judith M., Kenneth E. Barron, John M. Tauer, and Andrew J. Elliot. 2002. "Predicting Success in College: A Longitudinal Study of Achievement Goals and Ability Measures as Predictors of Interest and Performance from Freshman Year Through Graduation." Journal of Educational Psychology 94 (3): 562-575.

Hattie, John. 2009. Visible Learning. A Synthesis of Over 800 Meta-Analyses Relating to Achievement. London: Routledge. HEFCE. 2013. "Non-Continuation Rates at English HEls. Trends for entrants 2005-06 to 2010-11." Accessed May 12, 2017. http://www.hefce.ac.uk/pubs/year/2013/201307.

Hell, Benedikt, Manuela Linsner, and Günther Kurz. 2008. "Prognose des Studienerfolgs." In Studieneignung und Studierendenauswahl - Untersuchungen und Erfahrungsberichte, edited by Michael Rentschler, and Hans P. Voss, 132-177. Aachen: Shaker.

Heublein, Ulrich, and Andrä Wolter. 2011. "Studienabbruch in Deutschland. Definitionen, Häufigkeit, Ursachen, Maßnahmen." Zeitschrift für Pädagogik 57 (2): 214-236.

Howson, A. G., A. D. Barnard, D. G. Crighton, N. Davies, A. D. Gardiner, J. M. Jagger, D. Morris, J. C. Robson, and N. C. Steele. 1995. "Tackling the Mathematics Problem." Joint Report by London Mathematical Society, Institute of Mathematics and Its Applications, Royal Statistical Society. Accessed June 8, 2017. http://www.mei.org.uk/files/pdf/Tackling_the_ Mathematics_Problem.pdf.

Huang, Shaobo, and Ning Fang. 2013. "Predicting Student Academic Performance in an Engineering Dynamics Course: A Comparison of Four Types of Predictive Mathematical Models." Computers \& Education 61: 133-145.

Johnson, Marianne, and Eric Kuennen. 2006. "Basic Math Skills and Performance in an Introductory Statistics Course." Journal of Statistics Education 14 (2). http://ww2.amstat.org/publications/jse/contents_2006.html. 
Kadijevich, Djordje. 2006. "Developing Trustworthy TIMSS Background Measures: A Case Study on Mathematics Attitude." The Teaching of Mathematics 9 (2): 41-51.

Knospe, Heiko. 2011. "Der Eingangstest Mathematik an Fachhochschulen in Nordrhein-Westfalen von 2002 bis $2010 . "$ Proceedings 9. Workshop Mathematik für ingenieurwissenschaftliche Studiengänge. Wismarer Frege-Reihe (2): 8-13.

Kokkelenberg, Edward, and Esha Sinha. 2010. "Who Succeeds in STEM Studies? An Analysis of Binghamton University Undergraduate Students." Economics of Education Review 29: 935-946.

Kuncel, Nathan R., and Sarah A. Hezlett. 2007. "Standardized Tests Predict Graduate Students' Success." Science Education 315 (5815): 1080-1081.

Lawson, Duncan. 2000. "Changes in the Competency of A Level Students." In Measuring the Mathematics Problem, 6-9. London: The Engineering Council.

Ledermüller, Karl, and Irmgard Fallmann. 2017. "Predicting Learning Success in Online Learning Environments: SelfRegulated Learning, Prior Knowledge and Repetition." Zeitschrift für Hochschulentwicklung 12 (1): 79-99.

Macfadyen, Leah P., and Shane Dawson. 2010. "Mining LMS Data to Develop an 'Early Warning System' for Educators: A Proof of Concept." Computers \& Education 54 (2): 588-599.

Marbouti, Farshid, Heidi A. Diefes-Dux, and Johannes Strobel. 2015. "Building Course-Specific Regression-Based Models to Identify At-Risk Students." Proceedings of the American Society for Engineering Educators Annual Conference, Seattle,ID 11229.

Meyer, J. H. F., and Malcolm G. Eley. 1999. "The Development of Affective Subscales to Reflect Variation in Students' Experiences of Studying Mathematics in Higher Education." Higher Education 37: 197-216.

Mullis, Ina V. S., Michael O. Martin, Pierre Foy, and Alka Arora. 2012. "TIMSS 2011 International Results in Mathematics." TIMSS \& PIRLS International Study Center.

Pachman, Mariya, John Sweller, and Slava Kalyuga. 2013. "Levels of Knowledge and Deliberate Practice." Journal of Experimental Psychology: Applied 19 (2): 108-119.

Pant, Hans A., Petra Stanat, Ulrich Schroeders, Alexander Roppelt, Thilo Siegle, and Claudia Pöhlmann, eds. 2013. IQBLändervergleich 2012. Mathematische und naturwissenschaftliche Kompetenzen am Ende der Sekundarstufe I. Münster: Waxmann.

Pappano, Laura. 2012. "The Year of the MOOC." The New York Times, Education Life Supplement (Nov 4): 26.

Parsons, Sarah J., Tony Croft, and Martin Harrison. 2009. "Does Students' Confidence in Their Ability in Mathematics Matter?" Teaching Mathematics and Its Applications 28 (2): 52-68.

Pintrich, Paul R., and Elisabeth V. de Groot. 1990. "Motivational and Self-Regulated Learning Components of Classroom Academic Performance." Journal of Educational Psychology 82 (1): 33-40.

Pintrich, Paul R., David A. F. Smith, Teresa Garcia, and Wilbert J. McKeachie. 1991. A Manual for the use of the Motivated Strategies for Learning Questionnaire (MSLQ). Ann Arbor, MI: National Centre for Research to Improve Postsecondary Teaching and Learning.

Polaczek, Christa, and Gudrun Henn. 2008. "Vergleichende Auswertung des Mathematik-Eingangstests." University of Applied Sciences Aachen.

Rach, Stefanie, and Aiso Heinze. 2017. "The Transition from School to University in Mathematics: Which Influence Do School-Related Variables Have?" International Journal of Science and Mathematics Education 15 (7): 1343-1363.

Richardson, Michelle, Charles Abraham, and Rod Bond. 2012. "Psychological Correlates of University Students' Academic Performance: A Systematic Review and Meta-Analysis." Psychological Bulletin 138 (2): 353-387.

Robbins, Steven B., Kristy Lauver, Huy Le, Daniel Davis, Ronelle Langley, and Aaron Carlstrom. 2004. "Do Psychosocial and Study Skill Factors Predict College Outcomes? A Meta-Analysis." Psychological Bulletin 130 (2): 261-288.

Samson, Perry J. 2015. "Can Student Engagement be Measured? and, if so, Does it Matter?" Frontiers in Education Conference FIE.

Schiefele, Ulrich, and Klaus Peter Wild. 1994. "Lernstrategien im Studium: Ergebnisse zur Faktorenstruktur und Reliabilität eines neuen Fragebogens." Zeitschrift für Differentielle und Diagnostische Psychologie 15 (4): 185-200.

Sclater, Niall, Alice Peasgood, and Joel Mullan. 2016. "Learning Analytics in Higher Education: A review of UK and international practice." Bristol, MA: JISC Joint Information Systems Committee.

SEFI Mathematics Working Group. 2013. "A Framework for Mathematics Curricula in Engineering Education." Brussels: European Society for Engineering Education.

Smith, Glenn G., and David Ferguson. 2005. "Student Attrition in Mathematics e-Learning." Australasian Journal of Educational Technology 21 (3): 323-334.

Söderlind, Johan, and Lars Geschwind. 2017. "More Students of Better Quality? Effects of a Mathematics and Physics Aptitude Test on Student Performance." European Journal of Engineering Education 42: 445-457.

Street, Hannah. 2010. "Factors Influencing a Learner's Decision to Drop-Out or Persist in Higher Education Distance Learning." Online Journal of Distance Learning Administration 13 (4). https://www.westga.edu/ distance/ojdla/ winter134/street134.html.

Thiessen, Victor, and Jörg Blasius. 2008. "Mathematics Achievement and Mathematics Learning Strategies: Cognitive Competencies and Construct Differentiation." International Journal of Educational Research, 47 (6): 362-371.

Trapmann, Sabrina, Benedikt Hell, Sonja Weigand, and Heinz Schuler. 2007. “Die Validität von Schulnoten zur Vorhersage des Studienerfolgs - eine Metaanalyse." Zeitschrift für Pädagogische Psychologie 21 (1): 11-27. 
van Soom, Carolien, Vincent Donche, and Costa Manuel João. 2014. "Profiling First-Year Students in STEM Programs Based on Autonomous Motivation and Academic Self-Concept and Relationship with Academic Achievement." PLoS One 9 (11): e112489.

Winne, Philip H., and Dianne Jamieson-Noel. 2002. "Exploring Students' Calibration of Self Reports About Study Tactics and Achievement." Contemporary Educational Psychology, 27: 551-572.

Xie, Yu, and Kimberlee A. Shauman. 2005. Women in Science. Career Processes and Outcomes. Cambridge, MA: Harvard University Press.

Zhang, Guili, Timothy J. Anderson, Matthew W. Ohland, and Brian R. Thorndyke. 2004. "Identifying Factors Influencing Engineering Student Graduation: A Longitudinal and Crossinstitutional Study." Journal of Engineering Education 93: 313-320.

Zimmerman, Barry J., Adam Moylan, John Hudesman, Niesha White, and Bert Flugman. 2011. "Enhancing Self-Reflection and Mathematics Achievement of At-Risk Urban Technical College Students." Psychological Test and Assessment Modeling 53 (1): 141-160. 